\title{
Wnt Signaling and Forebrain Development
}

\author{
Susan J. Harrison-Uy ${ }^{1}$ and Samuel J. Pleasure ${ }^{1,2}$ \\ ${ }^{1}$ Department of Neurology, University of California, San Francisco, California 94143 \\ ${ }^{2}$ Programs in Neuroscience and Developmental Biology, Eli and Edythe Broad Center of Regeneration \\ Medicine and Stem Cell Research, University of California, San Francisco, California 94143 \\ Correspondence: sam.pleasure@ucsf.edu
}

Components of the Wnt signaling pathway are expressed in a tightly regulated and spatially specific manner during development of the forebrain, and Wnts are key regulators of regional forebrain identity. Wnt signaling from the cortical hem regulates the expansion and cell-type specification of the adjacent neuroepithelium and, in conjunction with Bmp, Fgf, and Shh signaling, controls dorsal-ventral forebrain patterning. Subsequently, Wnt signaling dynamically regulates the behavior of cortical progenitor cells, initially promoting the expansion of radial glia progenitor cells and later inducing neurogenesis by promoting terminal differentiation of intermediate progenitor cells. A role for Wnt signaling in cell-type specification has also been proposed.

$\mathrm{D}$ uring the initial specification of the telencephalon, discrete signaling centers are established through the actions of a series of interconnected signaling pathways. These signaling centers impart regional identity to the surrounding neuroepithelium, resulting in functional subdivision along the dorsal/ventral and rostral/caudal axes. These regional subdivisions allow diverse neural cell types to emerge from adjacent progenitor populations. Wnts are secreted glycoproteins that have been identified as key regulators of regional identity in the early developing forebrain. During subsequent cortical development, Wnt signaling in cortical progenitor cells (PCs) has also been implicated in cell cycle exit, neuronal differentiation, and establishing the laminar identity of excitatory neurons.

Although the various Wnt signaling pathways are described in great detail elsewhere in this collection, there are a few details that are relevant for this article that bear reiterating. In the canonical Wnt signaling pathway, secreted Wnt ligands bind to a Frizzled (Fzd)/low-density lipoprotein receptor-related protein (LRP) complex at the cell membrane. This complex recruits Dishevelled and inhibits the action of a pathway leading to the degradation of $\beta$ catenin. When degradation is blocked, $\beta$-catenin accumulates in the cytoplasm and subsequently translocates to the nucleus. In the nucleus, $\beta$-catenin interacts with the transcription factors T-cell factor (TCF)/lymphoid-enhancer factor (LEF) to modulate transcription of target genes (for review, see Logan and Nusse 2004; MacDonald et al. 2009; van Amerongen and Nusse 2009). There are also multiple non-canonical Wnt signaling pathways essentially independent of $\beta$-catenin, including the Wnt/calcium

Editors: Roel Nusse, Xi He, and Renee van Amerongen

Additional Perspectives on Wnt Signaling available at www.cshperspectives.org

Copyright (C) 2012 Cold Spring Harbor Laboratory Press; all rights reserved; doi: 10.1101/cshperspect.a008094

Cite this article as Cold Spring Harb Perspect Biol 2012;4:a008094 
pathway (for review, see Kuhl et al. 2000) and the planer cell polarity pathway (for review, see Seifert and Mlodzik 2007).

\section{WNT LIGAND AND SIGNALING COMPONENT EXPRESSION IN THE DEVELOPING FOREBRAIN}

Wnt ligands are expressed in discrete and overlapping patterns in the developing forebrain. By embryonic day 9.5 (E9.5) in the mouse, the neural tube has closed, and the telencephalon is located at the anterior segment of the neural tube. The expression of several Wnts can be detected in the forebrain at this age: Wnt1, Wnt3, Wnt3a, Wnt4, and Wnt7b in dorsal regions and $W n t 5 a$ and $W n t 7 a$ in ventral regions (Parr et al. 1993). Some of these genes have broad expression patterns, such as $W n t 7 b$, whereas others, such as $W n t 3 a$, show restricted expression patterns (Parr et al. 1993). Although LRP5/6 and several of the Frizzled receptors, including $F z d 1, F z d 2$, and $F z d 3$, are generally ubiquitously expressed in the early telencephalon (Pinson et al. 2000; Fischer et al. 2007), other Fzd receptors have more restricted patterns: Fzd4 and Fzd7 (dorsal telencephalic/diencephalic border), Fzd5 and Fzd8 (ventral telencephalon), Fzd9 and Fzd10 (dorsal telencephalon), and Fzd6 (dorsomedial telencepholon) (Fischer et al. 2007).

By E12.5, differentiated neurons have begun to appear in the cortex, and the PCs adjacent to the ventricles are regionally specified. Those in the dorsal cortex will produce excitatory neurons, followed by oligodendrocytes and astrocytes (Gorski et al. 2002). PCs in the ventral forebrain produce inhibitory interneurons, oligodendrocytes, and astrocytes (Wonders and Anderson 2005; Kessaris et al. 2006; Ono et al. 2008). The hippocampal anlage is located in the medial wall of the forebrain, adjacent to an important signaling center, the cortical hem (Grove et al. 1998). At this stage, expression of $W n t 2 b, W n t 3 a$, and $W n t 5 a$ is restricted to the cortical hem, whereas $W n t 7 a$ is expressed throughout the cerebral cortical ventricular zone but excluded from the cortical hem (Grove et al. 1998). $W n t 7 b$ and $W n t 8 b$ are expressed by the cortical hem and hippocampal anlage, although Wnt7b expression extends throughout the cortex in postmitotic neurons (Kim et al. 2001a; Theil 2005). Wnt7a and Wnt7b are expressed by PCs in the ventral telencephalon (Grove et al. 1998; Theil 2005; Fotaki et al. 2011). Fzd1 and Fzd2 are expressed in PCs in both the dorsal and ventral telencephalon, whereas $F z d 3$ is ubiquitously expressed in the telencephalon (Fischer et al. 2007). Fzd10 expression is restricted to the cortical hem (Kim et al. 2001b; Fischer et al. 2007). Fzd5\&8 and Fzd9 have complementary expression patterns: Fzd9 is strongly expressed in the hippocampal anlage with weak expression dorsal and lateral regions, whereas Fzd5\&8 is expressed in a strong-lateral to low-medial gradient (Kim et al. 2001b; Fischer et al. 2007). Figure 1 summarizes Wnt ligand (Fig. 1A) and Fzd receptor (Fig. 1B) expression in the mouse forebrain at E12.5.

Canonical Wnt signaling has been mapped in the developing forebrain using BAT-gal reporter mice, in which expression of $\beta$-galactosidase is under the control of seven TCF/LEF binding sites, thereby reflecting canonical Wnt signaling (Maretto et al. 2003). These mice showed that Wnt signaling is active in cortical PCs during early forebrain development in a high-medial to low-lateral pattern, and that as development progresses, cortical Wnt signaling decreases (Backman et al. 2005). Electroporation studies of Wnt-responsive elements driving fluorescent markers at midneurogenesis indicate that Wnt signaling is active in radial glia (RG) PCs and a subpopulation of intermediate PCs (IPCs); is down-regulated in differentiating cells as they migrate away from the ventricular zone; but is then reactivated in cortical neurons $24 \mathrm{~h}$ after they enter the cortical plate (Fig. 1C) (Woodhead et al. 2006; Munji et al. 2011). Immunohistochemistry studies identified that $\beta$ catenin is localized to the apical (ventricular) surface of cortical PCs, and colocalizes with Ecadherin and N-cadherin, markers of apical adherens junctions (Junghans et al. 2005; Stocker and Chenn 2006).

Wnt ligand expression changes postnatally, resulting in de novo expression or decreased expression of Wnt ligands. Wnt $2 b$ and Wnt5a, 
A

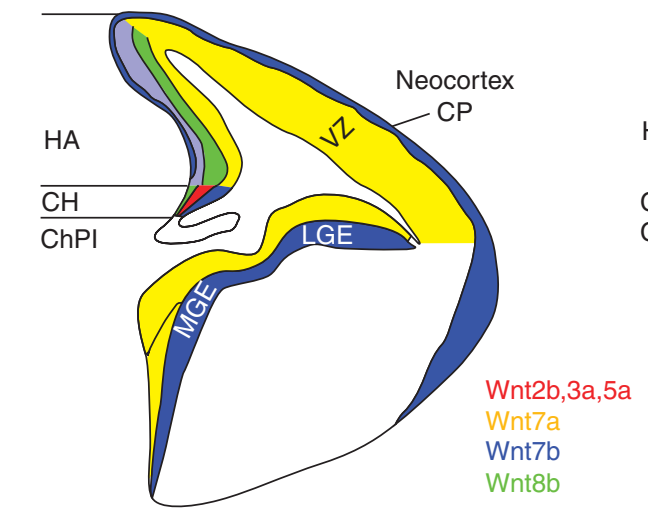

C

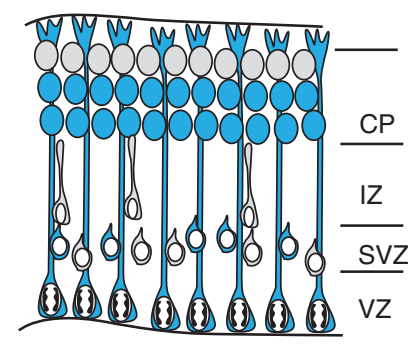

B

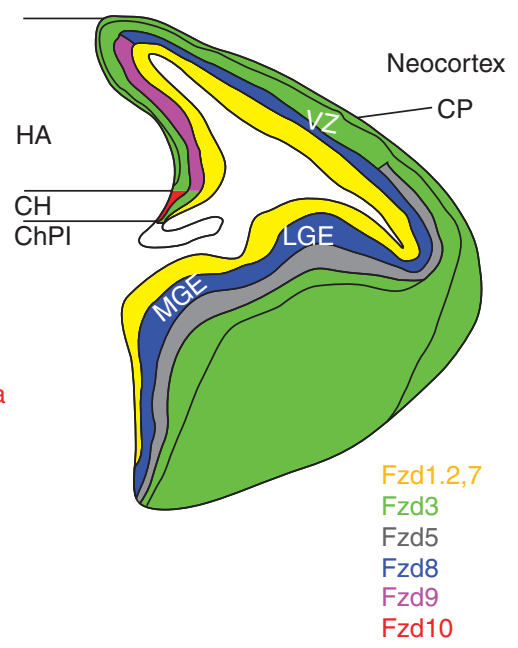

Figure 1. Expression of Wnt signaling components at E12.5 and E14.5. (A) Expression of Wnt ligands in the E12.5 telencephalon. $(B)$ Expression of Fzd receptors in the E12.5 telencephalon. $(C)$ At E14.5, Wnt signaling is active (blue) in radial glia in the VZ, a subpopulation of IPCs in the SVZ, down-regulated in migrating neurons in the IZ. Twenty-four hours after cells reach the $\mathrm{CP}$, they become Wnt responsive. Abbreviations: $\mathrm{ChPl}$, choroid plexus; $\mathrm{CH}$, cortical hem; HA, hippocampal anlage; VZ, ventricular zone; CP, cortical plate; LGE, lateral ganglionic eminence; MGE, medial ganglionic eminence; VZ, ventricular zone; SVZ, subventricular zone; IZ, intermediate zone.

which are confined to the cortical hem during embryonic development, are expressed in complementary layers in the postnatal somatosensory cortex (Wnt2b: layers IV and VI; Wnt 5a: layers II/III and V) (Shimogori et al. 2004b). $W n t 2 b$ expression continues in layer VI in the visual and auditory cortex, whereas Wnt5a expression in layers II/III and V is observed in the parietal and temporal cortex (Shimogori et al. 2004b). Wnt7b, which is expressed in the developing cortical plate (Kim et al. 2001a; Theil 2005), is expressed in a "complex lamina pattern" in the adult cortex (Shimogori et al. 2004b). Expression of Wnt7a is extinguished in the adult neocortex (Shimogori et al. 2004b). These studies indicate a dynamic regulation of members of the Wnt signaling pathway in the developing and adult forebrain and suggest potential roles in several stage-specific developmental events in the forebrain.

\section{WNT SIGNALING AND FOREBRAIN PATTERNING}

The developing forebrain is initially composed of a relatively homogeneous population of PCs. As development progresses, key signaling centers pattern the neuroepithelium, influencing the fate of the cells generated from different regions. As mentioned above, the cortical hem is a transient embryonic neuroepithelial structure located in the medial wall, between the hippocampal anlage and the chorid plexus, characterized by expression of Wnt and bone morphogenic 
protein (Bmp) family members (Furuta et al. 1997; Grove et al. 1998). It is now apparent that signaling from the cortical hem influences development of the adjacent hippocampal and cortical neuroepithelium and probably has longrange effects on the dorso-ventral patterning of the forebrain. These events and the role of the hem have been studied by analyzing Wnt signaling mutants and mice with altered cortical hem development.

Gli3, a downstream effector of Sonic hedgehog signaling, is disrupted in the mouse mutant extra-toes, resulting in severe alteration of the developing telencephalon (Hui and Joyner 1993; Franz 1994). In these mutant mice, the cortical hem fails to develop, and cortical hem-specific Wnt and Bmp expression is absent or severely reduced (Grove et al. 1998; Tole et al. 2000). Hippocampal markers Ephb1 and KA1 are absent from the medial wall of the developing telencephalon (Tole et al. 2000), and the hippocampus is not histologically evident in extra-toes mutants (Theil et al. 1999). Interestingly, although the forebrain choroid plexus does not express Gli3, it also fails to develop when Gli3 is disrupted, suggesting a role for signaling from the cortical hem in regulating the induction of the choroid plexus as well (Franz 1994; Grove et al. 1998). These studies suggest that the Wnt-rich cortical hem controls the development of adjacent cortical structures - the developing hippocampus and choroid plexus. It is likely that Bmp signaling collaborates with Wnts, at least in choroid plexus development, because mutants lacking almost all Bmp signaling in the developing cortex lack any evidence of lateral ventricle choroid plexus development (Hebert et al. 2002).

Analysis of embryos deficient for Wnt3a and Lef1 confirm a role for Wnt signaling in the development of the hippocampus. In the absence of Wnt3a, the cortical hem and choroid plexus are specified and Bmp signaling is maintained; however, the medial wall of the telencephalon is shorter (from E10.75 onward), and the choroid plexus has an abnormal morphology (at E12.5) (Lee et al. 2000). The hippocampus and dentate gyrus are not present at E18.5 in Wnt3a mutants, and markers of these structures, KA1 and Steel, are largely absent (remnants of CA1, CA3, and the subiculum can be detected at caudal levels) (Lee et al. 2000). Deletion of the transcription factor Lef1 (Lef1 knockout) results in essentially complete loss of the dentate gyrus and abnormal development of the CA fields of the hippocampus (Galceran et al. 2000). Disruption of Lef1 via insertion of a LacZ gene (Lef1 ${ }^{\text {lacZ/lacZ }} \mathrm{mu}$ tants), which in addition to disrupting the normal function of Lef1 generates a Lef1-lacZ fusion dominant interfering protein, results in a complete loss of both the dentate gyrus and hippocampus (Galceran et al. 2000). Proliferation studies using 5-bromo-2'-deoxyuridine (BrdU) to label proliferating cells identified a decrease in the number of $\mathrm{BrdU}^{+}$cells in the medial wall of the developing telencephalon at E10.5 (Wnt3a mutants) and E11.5 (Lef1 mutants), suggesting that Wnt signaling regulates the expansion of the hippocampal PC population by promoting proliferation of PCs (Galceran et al. 2000; Lee et al. 2000). This was confirmed by in vitro studies that showed that Wnt3a treatment of hippocampal PC cultures decreased the cell cycle length and increased the number of proliferating cells (Yoshinaga et al. 2010). These changes in the dynamics of PCs lead to an increase in the number of neurons after Wnt3a stimulation (Yoshinaga et al. 2010). Consistent with these studies, inactivation of $\beta$-catenin using D6-Cre, results in a shorter medial wall of the telencephalon and severe disruption of hippocampal fields CA1 and CA2 (Machon et al. 2003). Because D6-Cre results in the inactivation of $\beta$-catenin in the subiculum and CA1 fields but not in the cortical hem, CA3, and dentate gyrus (Machon et al. 2003), it supports a role for Wnt signaling in the target areas receiving Wnts expressed by the cortical hem. Interestingly, cell proliferation at E12.5 and E13.5 was not altered, which suggests that, whereas Wnt signaling may regulate the initial expansion of the neural epithelium giving rise to the hippocampus, ongoing proliferation of PCs may be independent of $\beta$-catenin-mediated signaling (Machon et al. 2003). In Wnt3amutants, Lef1 knockout, and mice with D6-Cre conditional inactivation of $\beta$-catenin, molecular 
markers of hippocampal cell types remain, suggesting that additional signaling pathways may influence cell fate specification. The complete loss of hippocampal and dentate gyrus markers in the Lef1 $1^{\text {lac } Z / \text { lac } Z}$ mutants raises the possibility that Lef1-mediated interactions may play a role in these alternative pathways.

Lhx2 is a homeobox gene expressed by cortical PCs throughout the cortex but excluded from the cortical hem (Nakagawa et al. 1999). Disruption of the $L h \times 2$ gene results in a smaller telencephalon and expansion of the cortical hem and choroid plexus (Bulchand et al. 2001; Monuki et al. 2001). Although previous studies suggested that the cortical hem is required for expansion of the hippocampal neuroepithelium, the hippocampus fails to form in $L h \times 2$ mutants (Bulchand et al. 2001). This apparent contradiction in function of the cortical hem in regulating hippocampal specification was examined using Lhx2 mosaic models (Mangale et al. 2008). This study suggests that Lhx2 functions as a cortical selector gene. Medially Lhx2negative tissue adopts a Wnt-expressing cortical hem fate and influences the surrounding Lhx2positive tissue to adopt a hippocampal (medial regions) or cortical (lateral regions) fate (Mangale et al. 2008). This is consistent with studies showing that sustained Wnt signaling in cortical PCs (via expression of a $\beta$-catenin/Lef1 fusion protein) results in ectopic expression of hippocampal markers in the lateral cortex (Machon et al. 2007). Thus, Wnt signals from the cortical hem acting on adjacent neuroepithelium are required for the initial expansion of the hippocampal anlage and influence the subsequent specification of hippocampal cell types.

In addition to a role for the Wnt-rich cortical hem in specifying the adjacent hippocampus, this signaling center can have long-range effects establishing the molecular identity of PCs in the dorsal/ventral axis. In extra-toes mutant mice, wherein Wnt and Bmp signaling in the cortical hem is disrupted, the cortical neuroepithelium expresses markers of the ventral telencephalon (Tole et al. 2000; Kuschel et al. 2003). These changes in extra-toes mutants are associated with ectopic expression of $F g f 8$ at the dorsal midline (Kuschel et al. 2003). Fgf signal- ing from the anterior telencephalon influences patterning along the anterior-posterior axis (Fukuchi-Shimogori and Grove 2001), and ectopic Fgf expression in the midline via in utero electroporation leads to decreased Wnt expression in the cortical hem (Shimogori et al. 2004a). The anterior Fgf8 expression is normally restricted by cortical hem Bmp signaling (Shimogori et al. 2004a). Similarly, in transgenic mice, ectopically expressing Sonic hedgehog in cortical PCs, Wnt expression in the cortical hem is absent, $F g f 8$ expression is expanded, and markers of the ventral telencephalon are expressed in the cortical neuroepithelium (Huang et al. 2007). Therefore, it seems that cross-regulation between Wnt, Bmp, FgF, and Shh signaling, produced by discrete signaling centers, is critical in controlling dorsal-ventral forebrain patterning.

Further evidence for the role of Wnt signaling in dorsal-ventral patterning was obtained from transgenic mice with altered expression of $\beta$-catenin. Loss of $\beta$-catenin in neural PCs from E8 resulted in expression of ventral restricted markers (Gsh2, Mash1, Dlx2/5) in cortical PCs (Backman et al. 2005). Loss of $\beta$-catenin in neural PCs from E11 did not alter the fate of PCs in the dorsal or ventral telencephalon, suggesting that the role of Wnt signaling in patterning the forebrain is relatively early (Backman et al. 2005). Expression of constitutively active $\beta$-catenin from E8 or E11 results in partial expression of dorsal-restricted markers in the ventral forebrain (most notably Ngn2) and a decrease in expression of ventral-restricted markers, suggesting that Wnt signaling may repress the molecular identity of ventral PC populations even at subsequent stages (Backman et al. 2005). The mechanism of Wnt regulation of dorsal/ventral patterning is not clear, but one likely possibility is the direct regulation of homeobox genes that are effectors of patterning. Emx2 is a direct target of Wnt signaling, and in extra-toes mutants, Emx1 expression is absent and Emx2 expression is decreased (Theil et al. 1999, 2002; Tole et al. 2000). In $\beta$-catenin loss-of-function mutants (E8), expression of Emx1 and Emx2 is decreased, and in $\beta$-catenin loss-of-function mutants (E11), Emx2 expression is decreased 
(Backman et al. 2005). Because Emx2 and Pax6 are expressed in opposing gradients and function in an opposing manner to regulate early positional identity in the developing forebrain (Bishop et al. 2002), this is probably one of the ways that Wnt signaling regulates cortical PC regional identity. Alterations in Wnt signaling components are also found in Pax6 mutants (Cho and Dressler 1998; Kim et al. 2001a; Muzio et al. 2002), and alterations in Pax6 expression are observed in $\beta$-catenin gain-of-function mutants (Backman et al. 2005), suggesting that Wnt signaling may be both upstream and downstream developmentally of the key regulators of dorsal/ventral patterning.

\section{WNT REGULATION OF RADIAL GLIA AND INTERMEDIATE PROGENITOR CELL FATE}

The properties of cortical PCs have been characterized using lineage tracing, live cell imaging, and genetic manipulation studies (Kriegstein and Noctor 2004; Guillemot 2005; Hevner 2006). Radially oriented cortical PCs (also called radial glia, RG) are located in a proliferative zone adjacent to the lateral ventricles. Early in cortical development, RGs undergo symmetric proliferative divisions, resulting in the production of two daughter RGs, thus expanding the PC population (Takahashi et al. 1996). As neurogenesis progresses RGs can undergo asymmetric divisions generating an RG and either a neuron or an intermediate progenitor cell (IPC) (Noctor et al. 2001, 2004; Haubensak et al. 2004; Miyata et al. 2004). IPCs migrate away from the ventricular surface and typically undergo symmetric divisions, resulting in the production of two neurons, thus expanding neuronal output (Noctor et al. 2004). By midcorticogenesis, terminal differentiation of IPCs represent the major means of neuron production (Noctor et al. 2004).

The continued expression of components of the Wnt signaling pathway after patterning events are complete suggests a role in subsequent developmental processes. In the presence of constitutively active Wnt signaling, via expression of a stabilized form of $\beta$-catenin, the forebrain is enlarged owing to a lateral expan- sion of the PC population and failure of asymmetric neuronal output (Chenn and Walsh 2002; Wrobel et al. 2007). Activation of Wnt signaling from E10.5, via expression of a $\beta$-catenin/Lef1 fusion protein, also inhibits cortical neural differentiation, whereas inactivation of $\beta$-catenin from E11 promoted terminal differentiation of PCs and produced early neurogenesis (Machon et al. 2007). Inactivation of $\beta$ catenin at E13.5 in cortical PCs by in utero electroporation resulted in an increase in the number of electroporated cells exiting the cell cycle, prematurely differentiating, and populating the cortical plate, compared with controls (Woodhead et al. 2006). These studies suggest a role for Wnt signaling in promoting symmetric proliferative divisions during early cortical development, expanding the PC population. In the event of failed Wnt signaling in the RG population, these cells instead apparently terminally differentiate and become neurons.

A role for Wnt signaling in regulating the maturation of RGs into IPCs has also been proposed. Some studies indicate that these effects on IPC dynamics may be predominantly secondary. Activation of Wnt signaling from E10.5 results in decreased IPC number, and IPC cell number is increased when Wnt signaling is lost from E10.5 (Machon et al. 2007; Mutch et al. 2010). Expression of constitutively active $\beta$-catenin from E10.5 expands the RG population by promoting symmetric proliferative divisions, and initially IPC number is decreased; however, as neurogenesis progresses, IPC number increases (Wrobel et al. 2007). Therefore, IPC production may just be delayed in these models and the observed alterations in the IPC population are secondary to the role for Wnt signaling in promoting the expansion of RG. However, because there is a precursorproduct relationship between RGs and IPCs, it can be difficult to isolate the effects of Wnts on IPC cells using genetic methodology lacking appropriately specific tools.

In marked contrast, other studies using nongenetic methodologies suggested that Wnt signaling may, under some circumstances, promote neuronal differentiation rather than preserving PC identity. In primary neuronal cultures, 
Wnt Signaling and Forebrain Development

Wnt7a or constitutively active $\beta$-catenin promoted neuronal differentiation (Hirabayashi et al. 2004). In utero electroporation of constitutively active $\beta$-catenin at E13.5 resulted in an increase in the number of cells that had migrated to the cortical plate after $48 \mathrm{~h}$, whereas inhibition of Wnt signaling led to an increase in the number of electroporated cells in the VZ after 48 h (Hirabayashi et al. 2004). Consistent with this role of Wnt signaling in promoting neurogenesis, expression of constitutively active $\beta$-catenin from E12.5 increased IPC number at the expense of RG number (Kuwahara et al. 2010). These findings may be due to a role of Wnt signaling in activating the pro-neural genes Ngn1\&2 and N-Myc (Hirabayashi et al. 2004; Israsena et al. 2004; Kuwahara et al. 2010).

In reconciliation of these two opposing roles of Wnt signaling in regulating cortical PCs, recent studies suggest that this pathway may have distinct effects on RG and IPCs. In utero electroporation of Wnt3a at E13.5 promotes expansion of the RG population, consistent with earlier studies; however, these studies identified an additional role for Wnt signaling in promoting the terminal differentiation of IPCs (Munji et al. 2011). Wnt3a promoted IPCs to differentiate into neurons, although these prematurely dif- ferentiated neurons failed to migrate properly to the cortical plate (Munji et al. 2011). Thus, the most consistent model is a temporal and lineage-dependent model for Wnt action, whereby the capacity of PCs to respond to Wnt signals changes as the PCs mature. Early in neurogenesis PCs (RGs) respond to Wnt stimulation by proliferating symmetrically, whereas later in development, although Wnt stimulation can still promote symmetric proliferation of RGs, it also induces neuronal differentiation by promoting terminal neurogenesis of IPCs (Fig. 2) (Hirabayashi et al. 2004; Hirabayashi and Gotoh 2005; Munji et al. 2011). These studies suggest a complex temporal and context-dependent control of Wnt signaling in distinct PC types.

\section{WNT SIGNALING AND CELL ADHESION}

In cortical PCs, $\beta$-catenin is localized to adherens junctions, associated with proteins that regulate cell adhesion, including $\mathrm{N}$-cadherin and E-cadherin (Junghans et al. 2005; Stocker and Chenn 2006). Loss of $\beta$-catenin from E9.0 or expression of a constitutively active form of $\beta$-catenin from E10.5 results in disruption of the integrity of the neuroepithelium architecture and loss of adherens junctions at the apical
A

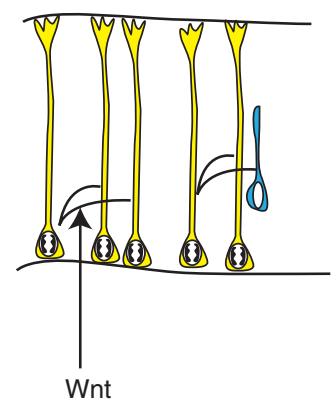

B

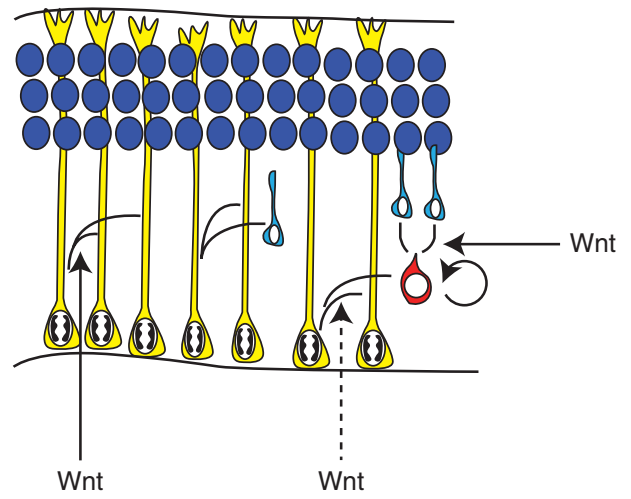

Figure 2. Wnt signaling promotes RG self-renewal and the differentiation of IPCs. (A) Early in cortical development (before E11.5), Wnt signaling promotes RG symmetric proliferative divisions, expanding the PC population. (B) During later cortical development (from E13.5), although Wnt signaling can still promote symmetric proliferative divisions, it also induces neurogenesis by promoting terminal neurogenesis of intermediate PCs. Wnt signaling may also promote the production of IPCs from RGs (B). (Yellow) RG; (red) IPC; (light blue) migrating neuron; (dark blue) mature neuron. 
surface (Junghans et al. 2005; Wrobel et al. 2007). Focal loss of E-cadherin or N-cadherin results in increased neuronal differentiation and is accompanied by a loss of Wnt signaling (Stocker and Chenn 2006; Zhang et al. 2010). This disruption in neurogenesis can be rescued by expression of a constitutively active form of $\beta$-catenin (Stocker and Chenn 2006; Zhang et al. 2010). Thus, in addition to a potential role for $\beta$-catenin in mediating cell-cell adhesion interactions in the developing forebrain, the interaction of $\beta$-catenin with cadherin molecules at adherens junctions may function to influence the dynamics of cell division type.

\section{WNT AND LAMINATION}

The cortex is a laminar structure containing six layers of cells that show distinct molecular characteristics, which is populated in an inside-out manner with deep layers born before moresuperficial layers (Angevine and Sidman 1961; Molyneaux et al. 2007). Wnt signaling has been implicated in laminar cell fate specification of cortical excitatory neurons. Activation of Wnt signaling in cortical PCs from E10.5 results in a loss of superficial cortical layers, whereas deep cortical layers are still generated (Wrobel et al. 2007). In utero electroporation of constitutively active $\beta$-catenin at E13.5 promotes a deep layer fate and inhibits the production of a superficial layer fate, whereas inhibition of Wnt signaling with a dominant-negative TCF construct had an opposite effect (Wrobel et al. 2007; Mutch et al. 2010). At E15.5, activation of Wnt signaling promoted a deep cortical fate at the expense of a superficial cortical fate (Mutch et al. 2010). In contrast, another study using the Wnt inhibitor Dkk1 identified that in utero electroporation at E13.5 inhibited the production of deep cortical layers, whereas in utero electroporation at E15.5 inhibited the production of superficial cortical layers, suggesting that Wnt signaling generally promotes neurogenesis, rather than exerting a specific role in laminar fate specification (Munji et al. 2011). All of these methods alter the dynamics of cortical PCs, and the phenotypes observed may reflect secondary effects, rather than a direct role for Wnt signaling in neural cell- type specification. Disruption of Wnt signaling specifically in postmitotic neurons should address the role of Wnt signaling in cortical laminar fate.

\section{WNT AND VENTRAL FOREBRAIN NEUROGENESIS}

Similar to its role in cortical PCs, Wnt signaling in the ventral forebrain regulates the expansion of PCs in the medial ganglionic eminence ( $\mathrm{Gu}$ lacsi and Anderson 2008). In the developing spinal cord, Wnt signaling regulates oligodendrocyte maturation (Fancy et al. 2009; Feigenson et al. 2009; Ye et al. 2009). The first wave of ventrally derived oligodendrocytes is produced in the medial ganglionic eminence/anterior entopeduncular area from E11.5 (Kessaris et al. 2006). Loss of the non-canonical Wnt receptor Ryk results in an increase in the production of early-born oligodendrocytes at the expense of GABAergic interneurons (Zhong et al. 2011). These studies also identified that Wnt3a stimulation promotes a neuronal fate over an oligodendrocyte fate, and Ryk is required for this response (Zhong et al. 2011). These findings suggest that in addition to regulating the expansion of PCs in the ventral forebrain, Wnt signaling controls cell-type specification as well.

\section{CONCLUSIONS}

Wnts play numerous roles at distinct developmental stages depending on the context of the receiving cells and the source and identities of the ligands. Following forebrain specification, Wnts contribute to anterior-posterior and dorsal-ventral patterning, similar to their role in other CNS regions and organ systems. The biggest contribution of Wnts in this process comes from the cortical hem, a signaling center that is a transient developmental source of several Wnt ligands. Once these domains are established, Wnts regulate the dynamic behavior of neural progenitor cells, first supporting symmetric, expansive stem cell divisions and later driving the differentiation of limited potential progenitors. Wnts are also involved in the cell fate decisions that these progenitors make as they differentiate. Thus, the future prospects for understanding 
how Wnts regulate all of these events in the nervous system are really dependent on understanding with which other signaling events Wnts intersect at each of these nodal steps. The next few years will certainly bring many of these interactions to light.

\section{ACKNOWLEDGMENTS}

This work is supported by grants from NIDA: R01 DA017627, NIMH: R01 MH077694, CIRM, and the National Multiple Sclerosis Society. We thank Julie Siegenthaler for her help with the figures.

\section{REFERENCES}

Angevine JB Jr, Sidman RL. 1961. Autoradiographic study of cell migration during histogenesis of cerebral cortex in the mouse. Nature 192: 766-768.

Backman M, Machon O, Mygland L, van den Bout CJ, Zhong W, Taketo MM, Krauss S. 2005. Effects of canonical Wnt signaling on dorso-ventral specification of the mouse telencephalon. Dev Biol 279: 155-168.

Bishop KM, Rubenstein JL, O’Leary DD. 2002. Distinct actions of Emx1, Emx2, and Pax6 in regulating the specification of areas in the developing neocortex. J Neurosci 22: $7627-7638$.

Bulchand S, Grove EA, Porter FD, Tole S. 2001. LIM-homeodomain gene $L h \times 2$ regulates the formation of the cortical hem. Mech Dev 100: 165-175.

Chenn A, Walsh CA. 2002. Regulation of cerebral cortical size by control of cell cycle exit in neural precursors. Science 297: 365-369.

Cho EA, Dressler GR. 1998. TCF- 4 binds $\beta$-catenin and is expressed in distinct regions of the embryonic brain and limbs. Mech Dev 77: 9-18.

Fancy SP, Baranzini SE, Zhao C, Yuk DI, Irvine KA, Kaing S, Sanai N, Franklin RJ, Rowitch DH. 2009. Dysregulation of the Wnt pathway inhibits timely myelination and remyelination in the mammalian CNS. Genes Dev 23: 1571-1585.

Feigenson K, Reid M, See J, Crenshaw EB III, Grinspan JB. 2009. Wnt signaling is sufficient to perturb oligodendrocyte maturation. Mol Cell Neurosci 42: 255-265.

Fischer T, Guimera J, Wurst W, Prakash N. 2007. Distinct but redundant expression of the Frizzled Wnt receptor genes at signaling centers of the developing mouse brain. Neuroscience 147: 693-711.

Fotaki V, Price DJ, Mason JO. 2011. Wnt/ $\beta$-catenin signaling is disrupted in the extra-toes $\left(\right.$ Gli $\left._{X t / X t}\right)$ mutant from early stages of forebrain development, concomitant with anterior neural plate patterning defects. J Comp Neurol 519: $1640-1657$.

Franz T. 1994. Extra-toes $(X t)$ homozygous mutant mice demonstrate a role for the Gli-3 gene in the development of the forebrain. Acta Anat (Basel) 150: 38-44.
Fukuchi-Shimogori T, Grove EA. 2001. Neocortex patterning by the secreted signaling molecule FGF8. Science 294: 1071-1074.

Furuta Y, Piston DW, Hogan BL. 1997. Bone morphogenetic proteins (BMPs) as regulators of dorsal forebrain development. Development 124: 2203-2212.

Galceran J, Miyashita-Lin EM, Devaney E, Rubenstein JL, Grosschedl R. 2000. Hippocampus development and generation of dentate gyrus granule cells is regulated by LEF1. Development 127: 469-482.

Gorski JA, Talley T, Qiu M, Puelles L, Rubenstein JL, Jones KR. 2002. Cortical excitatory neurons and glia, but not GABAergic neurons, are produced in the Emx1-expressing lineage. J Neurosci 22: 6309-6314.

Grove EA, Tole S, Limon J, Yip L, Ragsdale CW. 1998. The hem of the embryonic cerebral cortex is defined by the expression of multiple Wnt genes and is compromised in Gli3-deficient mice. Development 125: 23152325.

Guillemot F. 2005. Cellular and molecular control of neurogenesis in the mammalian telencephalon. Curr Opin Cell Biol 17: 639-647.

Gulacsi AA, Anderson SA. 2008. $\beta$-Catenin-mediated Wnt signaling regulates neurogenesis in the ventral telencephalon. Nat Neurosci 11: 1383-1391.

Haubensak W, Attardo A, Denk W, Huttner WB. 2004. Neurons arise in the basal neuroepithelium of the early mammalian telencephalon: A major site of neurogenesis. Proc Natl Acad Sci 101: 3196-3201.

Hebert JM, Mishina Y, McConnell SK. 2002. BMP signaling is required locally to pattern the dorsal telencephalic midline. Neuron 35: 1029-1041.

Hevner RF. 2006. From radial glia to pyramidal-projection neuron: Transcription factor cascades in cerebral cortex development. Mol Neurobiol 33: 33-50.

Hirabayashi Y, Gotoh Y. 2005. Stage-dependent fate determination of neural precursor cells in mouse forebrain. Neurosci Res 51: 331-336.

Hirabayashi Y, Itoh Y, Tabata H, Nakajima K, Akiyama T, Masuyama N, Gotoh Y. 2004. The Wnt/ $\beta$-catenin pathway directs neuronal differentiation of cortical neural precursor cells. Development 131: 2791-2801.

Huang X, Litingtung Y, Chiang C. 2007. Ectopic Sonic hedgehog signaling impairs telencephalic dorsal midline development: Implication for human holoprosencephaly. Hum Mol Genet 16: 1454-1468.

Hui CC, Joyner AL. 1993. A mouse model of Greig cephalopolysyndactyly syndrome: The extra-toes ${ }^{J}$ mutation contains an intragenic deletion of the Glizgene. Nat Genet 3: 241-246.

Israsena N, Hu M, Fu W, Kan L, Kessler JA. 2004. The presence of FGF2 signaling determines whether $\beta$-catenin exerts effects on proliferation or neuronal differentiation of neural stem cells. Dev Biol 268: 220-231.

Junghans D, Hack I, Frotscher M, Taylor V, Kemler R. 2005. $\beta$-Catenin-mediated cell-adhesion is vital for embryonic forebrain development. Dev Dyn 233: 528-539.

Kessaris N, Fogarty M, Iannarelli P, Grist M, Wegner M, Richardson WD. 2006. Competing waves of oligodendrocytes in the forebrain and postnatal elimination of an embryonic lineage. Nat Neurosci 9: 173-179. 
Kim AS, Anderson SA, Rubenstein JL, Lowenstein DH, Pleasure SJ. 2001a. Pax-6 regulates expression of SFRP-2 and Wnt-7b in the developing CNS. J Neurosci 21: RC132RC136.

Kim AS, Lowenstein DH, Pleasure SJ. 2001b. Wnt receptors and Wnt inhibitors are expressed in gradients in the developing telencephalon. Mech Dev 103: 167-172.

Kriegstein AR, Noctor SC. 2004. Patterns of neuronal migration in the embryonic cortex. Trends Neurosci 27: 392-399.

Kuhl M, Sheldahl LC, Park M, Miller JR, Moon RT. 2000. The Wnt $/ \mathrm{Ca}^{2+}$ pathway: A new vertebrate Wnt signaling pathway takes shape. Trends Genet 16: 279-283.

Kuschel S, Ruther U, Theil T. 2003. A disrupted balance between Bmp/Wnt and Fgf signaling underlies the ventralization of the Gli3 mutant telencephalon. Dev Biol 260: 484-495.

Kuwahara A, Hirabayashi Y, Knoepfler PS, Taketo MM, Sakai J, Kodama T, Gotoh Y. 2010. Wnt signaling and its downstream target $\mathrm{N}$-myc regulate basal progenitors in the developing neocortex. Development 137: 1035-1044.

Lee SM, Tole S, Grove E, McMahon AP. 2000. A local Wnt3a signal is required for development of the mammalian hippocampus. Development 127: 457-467.

Logan CY, Nusse R. 2004. The Wnt signaling pathway in development and disease. Annu Rev Cell Dev Biol 20: 781-810.

MacDonald BT, Tamai K, He X. 2009. Wnt/ $\beta$-catenin signaling: Components, mechanisms, and diseases. Dev Cell 17: 9-26.

Machon O, van den Bout CJ, Backman M, Kemler R, Krauss S. 2003. Role of $\beta$-catenin in the developing cortical and hippocampal neuroepithelium. Neuroscience 122: 129 143.

Machon O, Backman M, Machonova O, Kozmik Z, Vacik T, Andersen L, Krauss S. 2007. A dynamic gradient of Wnt signaling controls initiation of neurogenesis in the mammalian cortex and cellular specification in the hippocampus. Dev Biol 311: 223-237.

Mangale VS, Hirokawa KE, Satyaki PR, Gokulchandran N, Chikbire S, Subramanian L, Shetty AS, Martynoga B, Paul J, Mai MV, et al. 2008. Lhx2 selector activity specifies cortical identity and suppresses hippocampal organizer fate. Science 319: 304-309.

Maretto S, Cordenonsi M, Dupont S, Braghetta P, Broccoli V, Hassan AB, Volpin D, Bressan GM, Piccolo S. 2003. Mapping Wnt $/ \beta$-catenin signaling during mouse development and in colorectal tumors. Proc Natl Acad Sci 100: 3299-3304.

Miyata T, Kawaguchi A, Saito K, Kawano M, Muto T, Ogawa M. 2004. Asymmetric production of surface-dividing and non-surface-dividing cortical progenitor cells. Development 131: 3133-3145.

Molyneaux BJ, Arlotta P, Menezes JR, Macklis JD. 2007. Neuronal subtype specification in the cerebral cortex. Nat Rev Neurosci 8: 427-437.

Monuki ES, Porter FD, Walsh CA. 2001. Patterning of the dorsal telencephalon and cerebral cortex by a roof plateLhx2 pathway. Neuron 32: 591-604.
Munji RN, Choe Y, Li G, Siegenthaler JA, Pleasure SJ. 2011. Wnt signaling regulates neuronal differentiation of cortical intermediate progenitors. J Neurosci 31: 1676-1687.

Mutch CA, Schulte JD, Olson E, Chenn A. 2010. $\beta$-Catenin signaling negatively regulates intermediate progenitor population numbers in the developing cortex. PLoS ONE 5: e12376.

Muzio L, DiBenedetto B, Stoykova A, Boncinelli E, Gruss P, Mallamaci A. 2002. Emx2 and Pax6 control regionalization of the pre-neuronogenic cortical primordium. Cereb Cortex 12: 129-139.

Nakagawa Y, Johnson JE, O’Leary DD. 1999. Graded and areal expression patterns of regulatory genes and cadherins in embryonic neocortex independent of thalamocortical input. J Neurosci 19: 10877-10885.

Noctor SC, Flint AC, Weissman TA, Dammerman RS, Kriegstein AR. 2001. Neurons derived from radial glial cells establish radial units in neocortex. Nature 409: 714-720.

Noctor SC, Martinez-Cerdeno V, Ivic L, Kriegstein AR. 2004. Cortical neurons arise in symmetric and asymmetric division zones and migrate through specific phases. Nat Neurosci 7: 136-144.

Ono K, Takebayashi H, Ikeda K, Furusho M, Nishizawa T, Watanabe K, Ikenaka K. 2008. Regional- and temporaldependent changes in the differentiation of Olig2 progenitors in the forebrain, and the impact on astrocyte development in the dorsal pallium. Dev Biol 320: 456468.

Parr BA, Shea MJ, Vassileva G, McMahon AP. 1993. Mouse Wnt genes exhibit discrete domains of expression in the early embryonic CNS and limb buds. Development 119: 247-261.

Pinson KI, Brennan J, Monkley S, Avery BJ, Skarnes WC. 2000. An LDL-receptor-related protein mediates Wnt signalling in mice. Nature 407: 535-538.

Seifert JR, Mlodzik M. 2007. Frizzled/PCP signalling: A conserved mechanism regulating cell polarity and directed motility. Nat Rev Genet 8: 126-138.

Shimogori T, Banuchi V, Ng HY, Strauss JB, Grove EA. 2004a. Embryonic signaling centers expressing BMP WNT and FGF proteins interact to pattern the cerebral cortex. Development 131: 5639-5647.

Shimogori T, VanSant J, Paik E, Grove EA. 2004b. Members of the Wnt, $\mathrm{Fz}$, and Frp gene families expressed in postnatal mouse cerebral cortex. J Comp Neurol 473: 496510.

Stocker AM, Chenn A. 2006. Differential expression of $\alpha$-Ecatenin and $\alpha-\mathrm{N}$-catenin in the developing cerebral cortex. Brain Res 1073-1074: 151-158.

Takahashi T, Nowakowski RS, Caviness VS Jr. 1996. The leaving or $\mathrm{Q}$ fraction of the murine cerebral proliferative epithelium: A general model of neocortical neuronogenesis. J Neurosci 16: 6183-6196.

Theil T. 2005. Gli3 is required for the specification and differentiation of preplate neurons. Dev Biol 286: 559-571.

Theil T, Alvarez-Bolado G, Walter A, Ruther U. 1999. Gli3 is required for Emx gene expression during dorsal telencephalon development. Development 126: 3561-3571.

Theil T, Aydin S, Koch S, Grotewold L, Ruther U. 2002. Wnt and Bmp signalling cooperatively regulate graded $\mathrm{Emx} 2$ 
expression in the dorsal telencephalon. Development 129: 3045-3054.

Tole S, Ragsdale CW, Grove EA. 2000. Dorsoventral patterning of the telencephalon is disrupted in the mouse mutant extra-toes. Dev Biol 217: 254-265.

van Amerongen R, Nusse R. 2009. Towards an integrated view of Wnt signaling in development. Development 136 : 3205-3214.

Wonders C, Anderson SA. 2005. Cortical interneurons and their origins. Neuroscientist 11: 199-205.

Woodhead GJ, Mutch CA, Olson EC, Chenn A. 2006. Cell-autonomous $\beta$-catenin signaling regulates cortical precursor proliferation. J Neurosci 26: $12620-$ 12630 .

Wrobel CN, Mutch CA, Swaminathan S, Taketo MM, Chenn A. 2007. Persistent expression of stabilized $\beta$-catenin delays maturation of radial glial cells into intermediate progenitors. Dev Biol 309: 285-297.
Wnt Signaling and Forebrain Development

Ye F, Chen Y, Hoang T, Montgomery RL, Zhao XH, Bu H, Hu T, Taketo MM, van Es JH, Clevers H, et al. 2009. HDAC1 and HDAC2 regulate oligodendrocyte differentiation by disrupting the $\beta$-catenin-TCF interaction. Nat Neurosci 12: $829-838$.

Yoshinaga Y, Kagawa T, Shimizu T, Inoue T, Takada S, Kuratsu J, Taga T. 2010. Wnt3a promotes hippocampal neurogenesis by shortening cell cycle duration of neural progenitor cells. Cell Mol Neurobiol 30: 1049-1058.

Zhang J, Woodhead GJ, Swaminathan SK, Noles SR, McQuinn ER, Pisarek AJ, Stocker AM, Mutch CA, Funatsu N, Chenn A. 2010. Cortical neural precursors inhibit their own differentiation via $\mathrm{N}$-cadherin maintenance of $\beta$-catenin signaling. Dev Cell 18: 472-479.

Zhong J, Kim HT, Lyu J, Yoshikawa K, Nakafuku M, Lu W. 2011. The Wnt receptor Ryk controls specification of GABAergic neurons versus oligodendrocytes duringtelencephalon development. Development 138: 409-419. 


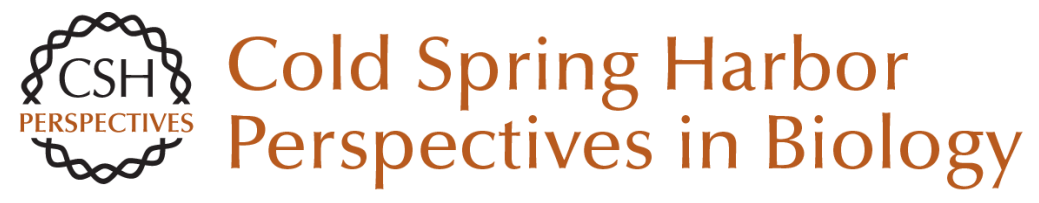

\section{Wnt Signaling and Forebrain Development}

Susan J. Harrison-Uy and Samuel J. Pleasure

Cold Spring Harb Perspect Biol 2012; doi: 10.1101/cshperspect.a008094 originally published online May 23, 2012

\section{Subject Collection Wnt Signaling}

Wnt Signaling in Vertebrate Axis Specification Hiroki Hikasa and Sergei Y. Sokol

Secreted and Transmembrane Wnt Inhibitors and

Activators

Cristina-Maria Cruciat and Christof Niehrs

Wnt Signaling in Normal and Malignant

Hematopoiesis

William Lento, Kendra Congdon, Carlijn Voermans, et al.

Frizzled and LRP5/6 Receptors for Wnt/ $\beta$-Catenin

Signaling

Bryan T. MacDonald and Xi He

TCF/LEFs and Wnt Signaling in the Nucleus

Ken M. Cadigan and Marian L. Waterman

\section{Alternative Wnt Pathways and Receptors \\ Renée van Amerongen}

$\beta$-Catenin-Dependent Wnt Signaling in $C$. elegans:

Teaching an Old Dog a New Trick

Belinda M. Jackson and David M. Eisenmann

The Evolution of the Wnt Pathway

Thomas W. Holstein
The $\beta$-Catenin Destruction Complex Jennifer L. Stamos and William I. Weis

Wnt Signaling in Skin Development, Homeostasis, and Disease Xinhong Lim and Roel Nusse

Wnt Signaling in Bone Development and Disease:

Making Stronger Bone with Wnts Jean B. Regard, Zhendong Zhong, Bart O. Williams, et al.

Targeting Wnt Pathways in Disease Zachary F. Zimmerman, Randall T. Moon and Andy J. Chien

Wnt Signaling in Mammary Glands: Plastic Cell

Fates and Combinatorial Signaling Caroline M. Alexander, Shruti Goel, Saja A. Fakhraldeen, et al.

Wnt Signaling and Injury Repair Jemima L. Whyte, Andrew A. Smith and Jill A. Helms

Wnt Signaling and Forebrain Development Susan J. Harrison-Uy and Samuel J. Pleasure

Wnt Signaling in Neuromuscular Junction Development

Kate Koles and Vivian Budnik

For additional articles in this collection, see http://cshperspectives.cshlp.org/cgi/collection/

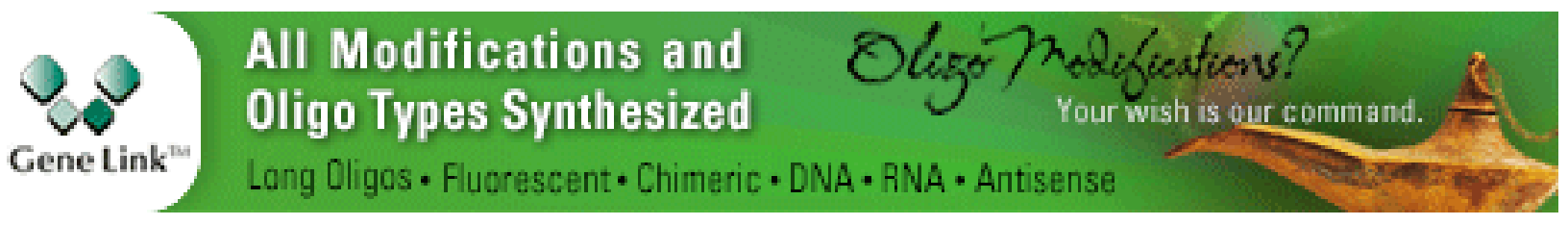

